\title{
A MEREOLOGICAL CHALLENGE TO
}

\section{ENDURANTISM}

\author{
Nikk Effingham and Jon Robson
}

In this paper, we argue that time travel is problematic for the endurantist. For it appears to be possible, given time travel, to construct a wall out of a single time travelling brick. This commits the endurantist to one of the following: (a) the wall is composed of the time travelling brick many times over; (b) the wall does not in fact exist at all; (c) the wall is identical to the brick. We argue that each of these options is unsatisfactory.

\section{Introduction}

The problem of temporary intrinsics is that persisting objects appear to hold incompatible properties. For instance, if Emmett is sitting and later he is standing then Emmett has the property of both sitting and standing. Endurantists can remove the contradiction by saying that Emmett is standing related to one time and sitting related to another time. Sider has argued that, given the possibility of time travel, this account fails to avoid the problem of temporary intrinsics [Sider 2001: 101 - 9]. His argument is this: if Emmett time travels back to meet himself and he is standing whilst his former self is sitting, then the same object is both sitting and standing related to one and the same moment and so a contradiction arises again.

However there are alternatives to this view of temporary intrinsics. The endurantist could regard intrinsic properties as momentary tropes [Ehring 1997] or distributional properties [Parsons 2004] and neither of these positions would be committed to quite the same problem. With this in mind we offer an objection to endurantism that is conditional on the possibility of time travel, but that does not rely on any controversial assumptions about 
the nature of temporary intrinsics. Instead it is argued that if time travel is possible and endurantism is true, problems arise concerning mereology, and in particular composition.

\section{The Time Travelling Brick}

Assume you are an endurantist. Imagine you are presented with what appears to be one hundred bricks, Brick1, Brick2, ..., Brick100, stacked together so as to arrange what appears to be a brick wall. The bricklayer, Marty, asks you whether the wall is a composite object or not. Presumably you will answer positively. However Marty claims that contrary to your intuitions the wall in question is not a composite object, and that he will demonstrate this. To begin his demonstration, Marty demolishes the wall. Let the time of the demolishing be t100. He then takes Brick1 to a nearby time machine, whereupon you both travel back in time to t1. Here Marty takes you to a shop and purchases a normal house brick, which he then places in the region that will be occupied by Brick1 at t100. Obviously Brick 1 is the brick purchased from the shop. Marty then places the future version of Brick1 from $t 100$ next to the past version of Brick1 so that it is in the region that will be occupied by Brick 2 at $\mathrm{t} 100$. Clearly then, Brick2 is numerically identical to Brick1. You both travel forward a hundred units of time to t101, where Marty takes Brick2 (which you now know to be Brick1 also), and then you both return to $\mathrm{t} 2$ where Brick2 is placed in the location where Brick3 will be. Travelling forward in time again to t102 Marty takes Brick3 (which you now know to be both Brick1 and Brick2) and travels back one hundred units of time to $\mathrm{t} 3$ where the brick is

placed in the location reserved for Brick4. This process is repeated until an entire wall has been constructed from the same object during the interval between $t 1$ and $t 100$. Likewise, Marty has removed 'different' bricks from the demolished wall leaving just a single brick at t200 (the brick originally purchased from the shop at t1).

In view of Marty's demonstration we do not think the endurantist can maintain that the wall is a composite object. As enduring objects are wholly present at every moment at which they exist, if Brick1, Brick2, ... , Brick100 composed a wall then it would be composed of just one object (since Brick1, Brick2, . . , Brick100 are all numerically identical to each 
other). This, as we will demonstrate in §III, is an unreasonable claim. Perhaps, then, the endurantist should give up his belief that the wall is indeed composite. In §IV, we show that this will not work either. If any wall is a composite object then the time travelling brick should compose a wall, so the endurantist is just a modus tollens away from denying the existence of any walls. Moreover, what works for walls works for every composite object, and the endurantist doesn't want to deny the existence of all composite objects. In §V we examine whether the endurantist could say that the brick simply is the wall, and show that this view is also counterintuitive. In §VI, we consider the claim that some part of our tale is impossible and argue that this move is detrimental to endurantism. As this exhausts all the options we conclude that endurantism fares significantly worse than perdurantism (which has no problems with this scenario).

\section{Why The Wall Is Not Composed Of The Brick}

There is a principle of mereology known as the Weak Supplementation Principle (WSP) which states that every object with a proper part has another proper part that does not overlap the first. ${ }^{1}$ If Brick1, Brick2, . . . Brick100 composed a wall, WSP would be false. Consider: any object that was part of the wall would have to overlap some brick, and as every brick is Brick1 if that object overlaps some brick the object must overlap Brick1. Therefore, if at $\mathrm{t} 100$ Brick1, Brick2, . . , Brick100 composed a wall, then there would be no object that could be a proper part of the wall that does not overlap Brick1. Given Brick1 is a proper part of that wall, WSP would then be false.

WSP is not only eminently plausible and in accord with our intuitions, but it is also an axiom of just about every mereology available. Indeed, Casati and Varzi write that

\footnotetext{
${ }^{1}$ By composite we mean more precisely 'properly composite' as objects always 'compose' themselves but never 'properly compose' themselves, analogous to how an object is always a part of itself but never a proper part of itself. We use 'composite' for the sake of expediency.
} 
'[s]ome authors (most notably Peter Simons) regard [WSP] as constitutive of the meaning of 'part' and would accordingly list it along with the lexical postulates of mereology' [Casati and Varzi 1999: 39]. So denying WSP is not a credible option.

But there is worse to come. Imagine the circumstances were different and Marty had built a wall such that it was composed of a time travelling brick which was identical to Brick1, Brick2, . . , Brick99, and then a non-time travelling brick that was Brick100. In this new scenario WSP is not threatened, but the following extremely plausible mereological principle fails: a composite object cannot have the same object as a proper part many times over. Call this the 'Parts Just Once' principle.

The only person to talk about the possibility of Parts Just Once being false is Lewis when he considers possible ways to explain structured universals. Lewis imagines that structured universals are mereological composites, e.g., being methane has other universals such as being hydrogen and the being bonded to relation as proper parts many times over [Lewis 1986: 91]. Lewis is incredulous about the idea, and rightly so. For the Parts Just Once principle to be false there could exist an $\mathrm{x}$ that has $\mathrm{n}$ proper parts, the $\mathrm{ys}$, (where $n>1$ ) such that the ys are not the same proper part, but are the same object. If there is a whole which has two or more different proper parts, the whole has those proper parts by being partrelated to two or more different (i.e., distinct) objects. So for each of the ys, that $y$ is not identical to any of the other ys. Yet it is stipulated that the same object (call it $\mathrm{z}$ ) is a part $\mathrm{n}$ times over. So $\mathrm{z}$ is identical to each of the ys - and so by the transitivity of identity each of the ys are identical to one another. A clear contradiction.

So the time travelling brick scenario not only breaches the almost universally accepted WSP, it also does considerable violence to our intuitions in rejecting the Parts Just Once principle.

On the other hand, perdurantists can accept the intuitive claim that the brick composes a wall without falling afoul of any of these problems. For the perdurantist the time travelling brick has numerous distinct temporal parts. When Marty constructs the wall the distinct temporal parts of the brick come to compose a temporal part of the wall. WSP doesn't fail since the wall has numerous distinct non-overlapping proper parts, namely the 
distinct temporal parts of the time travelling brick. The Parts Just Once principle is also respected because each temporal part of the brick is a part just once. So the perdurantist has a simple response to the scenario given in §II.

\section{Why The Wall Must Exist}

This section deals with the suggestion that Marty has failed to build a wall, and that endurantists should be mereological nihilists with regard to walls made of time travelling bricks. An endurantist who takes this position has a problem. Imagine a qualitatively identical wall composed just of mundane bricks: Brick101, . . Brick200. The arrangement of Brick101, . . Brick200 is the same as the arrangement of Brick1, .., Brick100. Brick101, .., Brick200 have the same causal connections as Brick1, . . , Brick100. Both walls would have the same function. Indeed, we cannot see how any reason can apply in one case but not the other (with one exception-that Brick1, ..., Brick100 are identical-we deal with this below). So if there is no reason for time travelling bricks to compose a wall, there is no reason for normal bricks to compose a wall. We assume that if there is no reason for the normal bricks to compose, then they don't. Therefore to be a mereological nihilist about walls made of time travelling bricks entails mereological nihilism about all walls.

There is one special reason why collections of mundane bricks might compose whereas collections of time-travelling bricks do not. The main difference between Brick1, .. , Brick100 and Brick101, . . , Brick200 is that Brick1, . ., Brick100 are identical and Brick101, ..., Brick200 are not. If the laws of composition can respect that difference, such that Brick1, . . . , Brick100 do not compose because they are identical and Brick101, . . , Brick200 do compose because they are distinct, then endurantism no longer has a problem. Unrestricted mereological composition (UMC) is just such a principle (and the only example of such a principle that we can think of). UMC states that a collection of objects (such as bricks) compose a distinct object (such as a wall) if and only if the objects in the collection do not mereologically overlap with one another [Markosian 1998]. Since Brick1, . . , Brick100 do mereologically overlap then according to UMC they should not compose a wall, whereas 
Brick101, . . , Brick200 should. This is exactly the conclusion that the endurantist would want. However things are not that simple. Typically the endurantist accepts that objects can change their parts over time, and that if the change in parts is gradual enough objects can change all of their parts over time. Imagine now that every time Marty returns to the past he waits until the brick is composed of entirely different atoms. The atoms that compose Brick1 are distinct from the atoms that compose Brick2 (and so forth for every brick). The atoms are distinct even though the 'bricks' they compose are not. So according to UMC all of the brick atoms compose an object, whereas the bricks do not. This is strange for now we do indeed have two composite walls but whilst one has atoms and bricks as parts, the other has only atoms even though the walls are qualitatively the same! More worryingly, whilst the endurantist no longer violates an axiom of mereology he does now violate a theorem of classical mereology (and hence a consequence of the logical properties of the parthood relation, WSP and UMC) that if the ys are part of an object $x$ then any object the ys compose is also a part of $x$ [Simons 1987: 38 - 41]. So if there is a wall composed of atoms, then the time travelling brick that some of the atoms compose must likewise be part of the wall-but this is exactly what the endurantist needs to avoid! So this special reason to prevent the composition of Brick1, .. , Brick100 also does not work.

The endurantist should not be a mereological nihilist about walls unless he wishes to be a mereological nihilist about everything because similar scenarios can be run for every object. Indeed, Feynman has suggested that this might be how objects in the actual world are [Feynman 1987]. Feynman theorizes that antiparticles could be normal particles travelling back in time. If Feynman is correct, then it is a routine possibility that objects are composed of the same time travelling particle. So if combining time travel and endurantism leads to mereological nihilism with respect to walls, then combining time travel and endurantism leads to nihilism about all objects. Since mereological nihilism is not a popular position (although it does have defenders [Hossack 2000; Dorr 2005]) most endurantists will not wish to endorse nihilism. Further, we will address the cost of nihilism in §VI. Let us then look at the remaining options for non-nihilist endurantists. 


\section{Why The Wall Cannot Be Identical To The Brick}

$\S I I I$ argued that you cannot claim that there is a wall composed of Brick1, . , Brick100 and $\mathrm{xIV}$ has argued that you cannot claim that there is no wall. There is another alternative, that there does exist a wall, but it is not composed of Brick1, . . , Brick100 but is instead identical to Brick1, ..., Brick100. So the wall that Marty builds is identical to the time travelling brick, it is just that the brick is pulling off the astonishing feat of being multi-located, which is unsurprising given its career as a piece of time travelling masonry. Call this the multilocation response.

We believe that this method fails. The time travelling brick would have to continue being a brick for some time after $\mathrm{t} 1$ and then, mysteriously, the brick would go from being merely a brick to also being a wall. So at $\mathrm{t} 100$ the brick is both a brick and a wall, both large and small, both weighs one kilogram and one hundred kilograms, and so forth. Our problem is not thatsuch an object would possess contradictory properties at the same time, for such apparent contradictions arise already, such as when Emmett time travels to meet his former, sitting, self. Since we have put aside Sider's argument for the purposes of presenting ours we must assume that the endurantist has a convincing method to allow us to accept these (alleged) contradictions. Our objections are different.

The first objection is that a brick is simply not the kind of thing that can be a wall. The endurantist may plausibly deny this, but the objection becomes more pressing in the case of other examples of time travelling objects. For instance, if a person comes to exist because we send a single particle in a time travelling loop the multi-location response means that a particle could be conscious, or that it could walk, talk, and pay taxes. This is exceedingly counterintuitive and far less plausible. Therefore even those who accept that a brick could be a wall will still face a more general problem.

The second objection is that this answer will be unsatisfactory for many endurantists who believe in sortal essentialism, the thesis that an object essentially falls under a certain sortal [Burke 1994; Wiggins 1980]. On the multi-location response, the brick is only accidentally a wall, a time travelling particle can accidentally be a person, and a man is only accidentally not an island (as you can send him back in time many, many times, rope him 
together, and give him some ballast). So there could be objects that do not fall under sortals essentially.

The third, and strongest, response is that at t100 the brick that weighs one kilogram is now identical to a wall that weighs one hundred kilograms. The endurantist must explain why the brick has suddenly got heavier. It cannot be that it has time travelled, for intuitively objects can time travel without gaining mass. It cannot be that it is multi-located, and that an object has a mass equal to the combined mass of all things it is identical to at that time. If an 11 stone Marty time travels so as to be standing next to his 5 stone former self then, while he may weigh 11 stone or 5 stone, he certainly does not weigh 16 stone. Nor can it be that the enduring object is suitably located in a spacetime such that it curves back on itself, for if it was arranged differently (for instance, if Brick1, . . , Brick100 were scattered about haphazardly) then there would be no wall, and the brick would not weigh one hundred kilograms. But it seems ridiculous that an object merely being located in one region rather than another can cause it to gain or lose mass.

Given all of these mysteries, the multi-location response is unattractive. The endurantist could accept each consequence, but this would engender excessive costs that the perdurantist could avoid.

\section{The Impossibility Response}

Finally, the endurantist could say that none of this is possible. Lewis [1976] argues that, when faced with logically impossible situations that can supposedly be brought about because of time travel, we should say that though time travel is possible, nevertheless these situations cannot in fact be brought about. Maybe the endurantist can say the same hereevery time Marty attempts to build walls made of time travelling bricks circumstances will conspire to prevent him. For example, he will be accidentally run over by his time-travelling future self whilst on his way to the brick shop. The lesson the endurantist could take from previous sections is that certain scenarios, such as building walls out of the same brick, or 
people out of Feynman-style particles, are impossible and that this poses no threat to endurantism or the possibility of time travel, any more than the impossibility of one assassinating one's own ancestors poses a threat to the law of non-contradiction or the possibility of time travel.

Or maybe it is impossible for other non-Lewisian reasons. Perhaps Marty can place his brick in the time machine but what appears in the past is just a duplicate, so there is no time travel-just backwards causation. Perhaps objects can never be multi-located as Brick1, . . . , Brick100 would have to be. Perhaps the endurantist will discard the possibility of backwards causation entirely. ${ }^{2}$ Or the endurantist may accept mereological nihilism: Marty cannot build a wall, because there are no walls, or bricks, at all. In all cases, the objection revolves around the impossibility of the wall building event.

All these points are well taken and it would be naive to suggest that our argument is the last nail in the coffin of endurantism. But it is a cost to endurantism for it cannot account for a conceivable scenario that perdurantism can easily account for [see also Sider 2001: 107]. Similarly it would seem to be a cost to endurantism to be committed to mereological nihilism when perdurantism is able to accommodate any theory of composition. So all the Impossibility Response is doing is merely acknowledging the cost we believe is incumbent upon endurantism to accept.

\section{Conclusion}

The endurantist encounters serious problems in combining his theory of persistence with the possibility of time travel. The perdurantist faces no such problems (although see Gilmore [2007] where similar scenarios, given separate considerations, are used to pose a problem for the perdurantist). We tend to believe, given the considerations of $x \mathrm{VI}$, that endurantists would be well advised to reject their theory of persistence rather than deny time travel or

\footnotetext{
${ }^{2}$ Note that these responses leave open the possibility of an empirical falsification of endurantism: if we go back and build a wall out of time travelling bricks then it is a possibility and ipso facto endurantism would be false.
} 
accept nihilism. Regardless, we have shown that the tensions between endurantist theories of persistence and belief in the possibility of time travel run deeper than had been previously realized. Further this tension can be motivated without recourse to Sider's claim that endurantists should treat properties as relations to times. ${ }^{3}$

\section{References}

Burke, M. 1994. Preserving the Principle of One Object to a Place: A Novel Account of the Relations Among Objects, Sorts, Sortals, and Persistence Conditions, Philosophy and Phenomenological Research 54: 591 - 624.

Casati, R. and A. Varzi 1999. Parts and Places, London: MIT Press.

Dorr, C. 2005. What We Disagree About When We Disagree About Ontology, in Fictionalism in Metaphysics, ed. M. Kalderon: 203 - 33.

Ehring, D. 1997. Lewis, Temporary Intrinsics and Momentary Tropes, Analysis 57: 254 - 8.

Feynman, R. 1987. The Reason For Antiparticles, in Elementary Particles and the Laws of Physics: The 1986 Dirac Memorial Lectures, ed. R. Feynman and S. Weinberg, Cambridge: Cambridge University Press: $1-59$.

Gilmore, C. 2007. Time Travel, Coinciding Objects, and Persistence, Oxford Studies in Metaphysics 3, ed. D. Zimmerman, Oxford: Clarendon Press: 177 - 98.

Hossack, K. 2000. Plurals and Complexes, British Journal for Philosophy of Science 51: 411 - 43.

Lewis, D. 1976. The Paradoxes of Time Travel, American Philosophical Quarterly 13: 145 - 52.

\footnotetext{
${ }^{3}$ We would like to thank Ross Cameron, George Darby, Mark Effingham, Walden Effingham, Robin le Poidevin, Jonathan Tallant, Duncan Watson, RobbieWilliams, the Leeds Work In Progress seminar, and the anonymous referees and editor for their advice and help with this paper. We give a special thanks to Joseph Melia for his invaluable help and aid.
} 
Lewis, D. 1986. Against Structural Universals, in Papers in Metaphysics and Epistemology, Cambridge: Cambridge University Press: 78 - 107.

Markosian, N. 1998. Brutal Composition, Philosophical Studies 92: 211 - 49.

Parsons, J. 2004. Distributional Properties, in Lewisian Themes, ed. F. Jackson and G. Priest, Oxford: Clarendon Press: 173 - 80.

Sider, T. 2001. Four-Dimensionalism, Oxford: Clarendon Press.

Simons, P. 1987. Parts: A Study in Ontology, Oxford: Clarendon Press.

Wiggins, D. 1980. Sameness and Substance, Cambridge, MA: Harvard University Press. 